\title{
FAULT DIAGNOSIS OF WIND POWER MACHINERY IN THE CONTEXT OF BIG DATA AND ARTIFICIAL INTELLIGENCE
}

\author{
LiLi Geng \\ Experiment Centre, Shanxi University of Finance and Economics, Taiyuan, 030006, China. \\ Email: genglili3sx@yeah.net
}

\begin{abstract}
To ensure the healthy, safe, and stable operation in the design working life, a gear box safe operation remote monitoring model is designed based on modern sensing, computer detection, wireless communication, and big data analysis. It is of great significance to realize the early diagnosis and early warning of gearbox fault and to improve the reliability and safety of the whole wind turbine operation. First, the mechanical structure and operation characteristics of the gearbox are studied, and the failure of the mechanical mechanism is analysed. Then, based on this fault situation, a set of monitoring scheme and fault diagnosis, including mechanical vibration analysis and on-site video monitoring, is proposed. Finally, the hardware and software of the model as well as digital signal processing module are designed to collect and process the data of various sensors. ARM is responsible for data storage and data display. WEB server provides convenience for wind turbine operation and maintenance personnel to perform fault monitoring, analysis and diagnosis in real time in the background. SIM900A is responsible for remote data transmission. Through actual experiments, under the background of big data, the fault detection of wind turbine gearbox in the operation process is realized, and mechanical accidents caused by gear wear and aging are avoided to a large extent. The operation of the gear is guaranteed and the safety is improved, making it more stable and real-time. Moreover, the operation and maintenance costs of enterprises are reduced. In short, intelligent analysis of wind turbines through big data can ensure the safe operation of the gearbox, which has reference significance for the healthy progression of wind power industry.
\end{abstract}

Keywords: Wind Turbine Generator; Gearbox; Intelligent Detection; Vibration Analysis; Big Data Analysis.

\section{Introduction}

The energy problem is the most concerned problem in the world today. At present, the energy utilized by human beings is mainly traditional fossil energy such as coal, oil, and natural gas. They are all nonrenewable resources that the earth has been forming over hundreds of millions of years. With the progression of human society, the rapid growth of economy and population leads to the rapid growth of energy consumption demand. Studies showed that the reserves of fossil energy on the earth were limited. If we continue to exploit and utilize these energy resources on a large scale without limit, human beings will soon face the problem of energy exhaustion. Moreover, the large-scale exploitation and utilization of fossil energy has caused very serious damage to the earth's ecological environment. Water pollution, air pollution, and other problems have plagued the survival and progression of human beings. How to solve the contradiction between energy shortage and human society's ever-increasing demand for energy and ease the problem of environmental pollution is a major issue facing all countries in the world. It is an urgent task to develop and utilize new energy sources and actively seek renewable alternative energy sources. The most common sources of renewable energy today are solar, wind, hydro, geothermal, nuclear, and tidal. With the progress of human science and technology, large-scale progression and utilization of new energy has become a reality. Among these new energy sources, wind energy has the advantages of wide distribution, huge amount, mature technology, and no pollution [1]. By the end of 2012, the accumulative installed capacity of wind power in China was as high as $62.36 \mathrm{GW}$ [2], accounting for $5.3 \%$ of the total power grid connection in China. The total amount of wind power has exceeded nuclear power, ranking among the three major power sources in China along with coal power and hydropower.

However, with the rapid progression of wind power, the related operation and maintenance work has not kept up with it, especially in the aspect of online monitoring of the safe operation condition of 
wind power units. With the increase of wind turbine operating time, the unit equipment has entered the fatigue period, and the failure rate has also increased significantly. As a large-scale equipment, wind turbines will cause irreparable losses in the event of a safety accident $[3,4]$. The traditional maintenance method of wind turbine is relying on manual maintenance on a regular basis, which increases the labour cost on the one hand. On the other hand, manual maintenance is greatly affected by the professional quality of maintenance personnel, and there is no set of scientific and quantitative measurement standards. Therefore, the traditional maintenance method isn't able to meet the safety needs of wind power generation. In this context, this research aims to develop a remote monitoring model for the safe operation of wind turbine gearbox to realize the remote online safety monitoring of wind turbine equipment.

\section{Scheme Design and Treatment 2.1 Wind Turbine Generator Gearbox Working Environment}

As the transmission equipment in wind power generation equipment, the gearbox is mainly composed of rotating shafts, gears, and bearings. Bearings are affected by various factors such as lubrication failure and stress concentration during the working process, and are prone to defects such as fatigue, pitting, and surface spalling cracks. Its working status is affected, which in turn causes great hidden dangers to the safe operation of the whole equipment $[5,6]$. Specific analysis of the source and characteristics of the failure of the main components of the gearbox is as follows.

I. Gear failure.

Figure 1 presents that gear failures mainly include tooth profile errors, tooth surface wear, fatigue spalling, pitting, plastic deformation, and broken teeth. In the process of gear meshing, the tooth surface is subjected to alternating pressure stress and frictional force. Insufficient lubrication or failure will cause wear to the tooth surface [7]. If the stress on the gear exceeds the fatigue limit of the gear material, cracks will occur on the gear surface. If it is not replaced or repaired in time, the cracks will gradually fall off and cause pitting corrosion. If the gear is operated under heavy load for a long time, or is subjected to an external instantaneous impact, the internal stress of the gear will greatly exceed the stress range of the material. Then, it is very easy to produce serious gear failures, including tooth surface cracks and irreversible plastic deformation. In severe cases, gear fractures may occur.

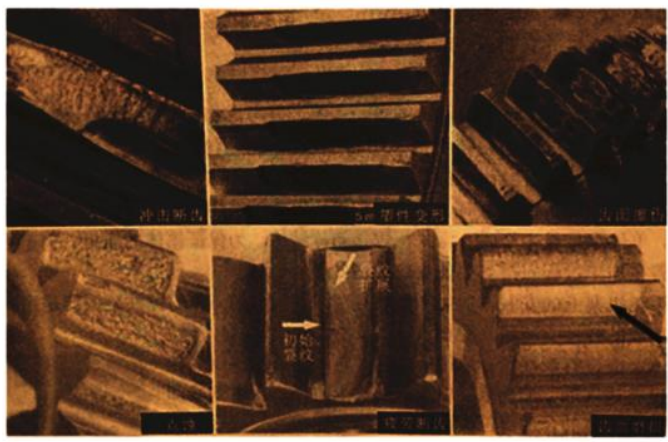

Figure 1: Typical mechanical failure forms of gears

\section{Bearing failure.}

Bearings and gears similarly have multiple failure forms such as surface wear, fatigue peeling, pitting, and plastic deformation [8]. The mechanism of bearing pitting corrosion is similar to that of gears. It is caused by long-term alternating compressive stress, which exceeds the fatigue limit of the material and forms cracks on the surface. As the bearing continues to run, the cracks propagate and eventually peel off to form pitting corrosion.

III. Rotating shaft and other malfunctions.

The failure of the shaft is mainly due to eccentricity. Due to insufficient rigidity and strength of the base and uneven load distribution, the gearbox shaft deviates from the generator shaft. This kind of deviation is called static eccentricity, and its consequence is the vibration of the drive shaft. Although the drive shaft usually has cushioning components, it doesn't completely eliminate the impact of the drive shaft vibration, which can cause damage to the entire gearbox. Under gust conditions or other instantaneous impact loads, the gearbox bearings will shift, resulting in dynamic eccentricity. It will also cause the drive shaft to vibrate and cause damage to the gearbox mechanism. In addition to these failure forms mentioned, there are also fault forms in the gearbox such as tooth profile error, box resonance, mild shaft bending, shaft imbalance, severe shaft bending, and axial movement $[9,10]$.

\subsection{Components of Wind Turbine Generator Monitoring Model}

Wind turbine generator gearbox vibration signal analysis includes time domain analysis and frequency domain analysis. Time domain analysis refers to the observation and analysis of a series of parameters such as the vibration amplitude, rate of change, and waveform shape of the time domain waveform, as well as various time domain statistical methods [11]. Time domain analysis indicators mainly include maximum value, minimum value, peak-to-peak value, mean value, mean square value, variance, mean square deviation, and kurtosis [12]. 
The time domain analysis method is simple and intuitive, which is also easy to understand. However, the time domain analysis method can't effectively perform quantitative analysis. It can only make a rough fault judgment, and can't locate the fault or judge the severity of the fault. The frequency domain analysis method transforms the time domain signal into the frequency domain, and can obtain the various frequency components contained in the signal and the relative size of each frequency component $[13,14]$. Under normal working conditions, mechanical parts have their inherent vibration frequency and amplitude.

The frequency domain signal is analysed. If the frequency domain signal only contains the natural frequency components of the component, then the component is working normally. If the frequency signal contains frequency components other than the natural frequency, then it is basically judged that this frequency component is a fault frequency component. The fault location and fault type can be located according to the value of the fault frequency, and the severity of the fault can be obtained according to the magnitude of the fault frequency [15].

For the gearbox, the vibration signal of each part of the gearbox is stable under normal working conditions if the external noise interference is not considered. The main frequency components of the vibration signal are the rotation frequency of each shaft and the meshing frequency of the gears [16,17]. When a failure occurs in a certain part, the vibration signal parameters such as frequency, amplitude, and phase may be modulated on the failure frequency and change.
Through the analysis of the vibration signal, the fault range and nature of the gearbox are obtained $[18,19]$.

I. Overall design of wind turbine generator monitor

The overall structure diagram of the remote monitoring model for safe operation of the wind turbine generator gearbox is shown in Figure 2. It is mainly composed of three modules, namely DSP data acquisition and processing module, ARM humancomputer interaction and video processing module, and remote WEB server module. DSP module is responsible for data acquisition and processing of vibration sensors, temperature sensors, and smoke detection sensors. It sends the collected raw data and data after analysis and processing to the ARM module for storage and display. In addition to storing and displaying data, the ARM module is also responsible for human-computer interaction. It also controls the USB camera for video surveillance and video speed measurement. All collected data are sent to the background WEB server through wireless transmission. The most commonly utilized GPRS method is selected for wireless data transmission, which is with low cost, easy to implementation, and is stable and reliable $[20,21]$. The WEB server collects information about the running status of the gearbox, and performs corresponding data processing and analysis. Wind power plant operation and maintenance personnel can use the browser to view the current operating status of the gearbox in real time.

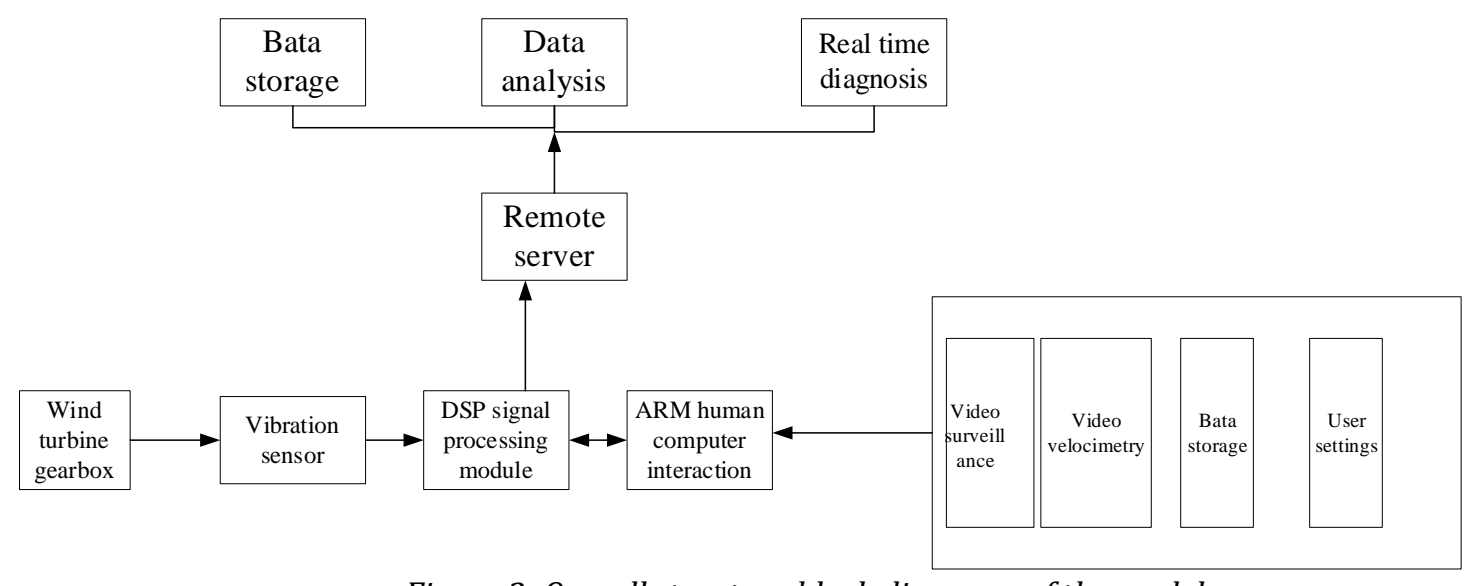

Figure 2: Overall structure block diagrams of the model

According to the analysis of the gearbox operating conditions and fault characteristics, it is concluded that the gearbox has a variety of fault forms and potential safety hazards, including mechanical vibration faults and other environmental abnormalities. The goal of this research is realizing the remote monitoring of the safe operation of the gearbox. Therefore, it is necessary to start from these four aspects, and adopt vibration monitoring and video monitoring methods to conduct a comprehensive monitoring and analysis of the operation status of the gearbox.

a. Vibration monitoring.

Vibration signal acquisition methods include acceleration sensors, displacement sensors, and speed sensors. In this research, the acceleration 
sensor is employed to collect the vibration of the gearbox. Commonly utilized acceleration sensors are classified into piezoelectric acceleration sensors, piezoresistive acceleration sensors, capacitive acceleration sensors, and servo acceleration sensors according to their working principles. Piezoelectric acceleration sensors are the most widely utilized. The piezoelectric acceleration sensor is made according to the principle of piezoelectric effect. When the crystal receives an external force, a polarization phenomenon is generated inside the crystal to generate a voltage on the surface of the crystal. This voltage is positively related to the size of the external force experienced by the crystal. Therefore, the acceleration can be obtained by measuring the voltage.

b. Video surveillance.

In addition to mechanical failures, abnormal lubrication system oil temperature, and fire hazards, there are still various problems in fan gearboxes and engine rooms. It is difficult to find a monitoring method that can cover all failure forms. Only by allowing wind turbine operation and maintenance personnel to browse the running screen inside the engine room in real time can they find various problems and take corresponding measures. The cabin video monitoring module can realize this function. Currently commonly utilized surveillance cameras include ordinary cameras and web cameras. As the name implies, the webcam can transmit video data through a network cable, and it can be equipped with a pan-tilt to achieve 360-degree monitoring. However, most of the webcams are expensive and require a network cable. Common cameras mostly use the USB interface. Although the monitoring angle is fixed, the data transmission rate is high, the operation is simple, and the cost is low. Therefore, a common USB camera is selected to realize the cabin video surveillance. Since it is a remote monitoring model, there is a remote wireless data transmission module, which can realize the network transmission of camera data.

II. Gearbox speed measurement.

a. Purpose of speed measurement.

The vibration signals of various parts of the gearbox are collected, the vibration signals in the frequency domain are analysed, and the gearbox operating status and fault conditions are determined according to its frequency components. As long as the speed of the main shaft of the wind turbine (the blades) is known, the speed of each part can be calculated through calculation.

b. Scheme design of video speed measurement.

In this research, video speed measurement is conducted to obtain blade speed through image processing algorithms such as object recognition. Figure 3 shows that the blade rotates continuously, and the current rotational speed of the fan blade is calculated by recording the time interval between two successive detections of the blade.

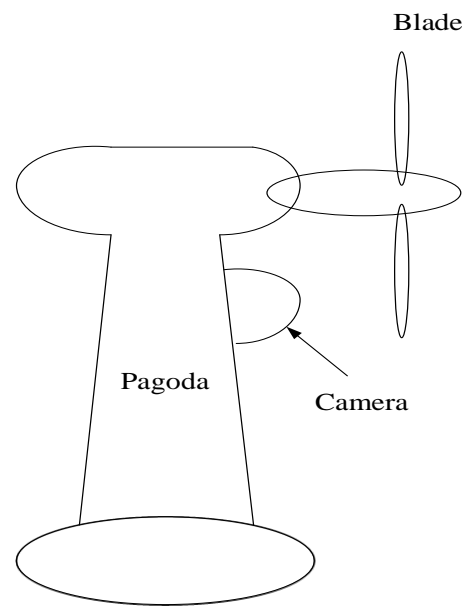

Figure 3: Schematic diagrams of the video speed measurement process and principle

III. Vibration monitoring module design.

Acceleration sensor selection and technical indicators are explained as follows. The technical indicators of the acceleration sensor include range, sensitivity, and measurement bandwidth. In this research, the vibration acceleration of the gearbox measured is not very large, about $2 \mathrm{~g}$, but the sensitivity requirements are relatively high. The vibration frequency of the gearbox is in the range of $0 \sim 800 \mathrm{~Hz}$, and the working voltage of the whole system is $3 \mathrm{~V}$. Since most of the fans are located in remote areas and the temperature range varies greatly, the selected acceleration sensor has a larger operating temperature range. After comprehensive comparison, the ADXL337 piezoelectric three-axis acceleration sensor produced by AD company is selected. ADXL337 provides a small size package in the form of $3 \mathrm{~mm} \times 3 \mathrm{~mm} \times 1.45 \mathrm{~mm}$ LFCSP, which is convenient for multi-point installation on the surface of the gear box. The power supply voltage of the chip is a wide range of $1.8 \sim 3.6 \mathrm{~V}$, and the measurement sensitivity is $300 \mathrm{mV} / \mathrm{g}$. There is a signal conditioning circuit inside the chip, which can directly output the conditioned analogue voltage to the subsequent $\mathrm{AD}$ conversion module. As the internal functions of ADXL337 chip, it has three outputs $\mathrm{X}_{\text {out, }} \mathrm{Y}_{\text {out, }}$ and $\mathrm{Z}_{\text {out }}$. Capacitors $C_{x}, C_{y}$, and $C_{z}$ are utilized to adjust the signal bandwidth of the corresponding channel. The bandwidth of $\mathrm{X}$-axis and $\mathrm{Y}$-axis is in the range of $0.5 \sim 1600 \mathrm{~Hz}$, and the bandwidth of Z-axis is in the range of $0.5 \sim 550 \mathrm{~Hz}$. The corresponding bandwidth calculations of the chip under the condition of $3 \mathrm{~dB}$ cut-off frequency areas follows.

$$
\begin{aligned}
& f_{-3 d B}=\frac{C_{(\mathrm{X}, \mathrm{Y}, \mathrm{Z})}}{2 \pi^{*} 32 k \Omega} \\
& f_{-3 d B}=\frac{5 \mu F}{C_{(\mathrm{X}, \mathrm{Y}, \mathrm{Z})}}
\end{aligned}
$$

From equation (2), when the capacitance $C_{x}$ and $\mathrm{C}_{\mathrm{y}}$ is $0.0033 \mathrm{uF}$, the bandwidth in the $\mathrm{X}$ and $\mathrm{Y}$ directions reaches the maximum $1600 \mathrm{~Hz}$. When the 
capacitance $\mathrm{C}_{\mathrm{z}}=0.01 \mathrm{uF}$, the bandwidth in the $\mathrm{Z}$ direction reaches the maximum $550 \mathrm{~Hz}$.

IV. Design of ARM human-computer interaction and DSP module.

LM2576 is currently the most widely utilized integrated voltage regulator chip, the maximum regulated output current is $3 \mathrm{~A}$, and the conversion efficiency can reach $88 \%$. LM2576 also has complete protection circuits such as current limit and thermal shutdown. When a circuit is designed, only a few peripheral components are needed to form a typical application circuit. The external power supply of the ARM board comes from an external $12 \mathrm{~V}, 0.8 \mathrm{~A}$ switching power supply. Then, the voltages of $5 \mathrm{~V}$ and $3.3 \mathrm{~V}$ are obtained through the voltage regulator modules LM2576-5 and LM2576-3.3 on the board, respectively. The $5 \mathrm{~V}$ regulated output voltage is provided to the serial port, USB interface, LCD drive circuit, etc., and the $3.3 \mathrm{~V}$ regulated output voltage is provided to other modules on the board.

In this research, MP1541DJ chip is selected to realize LCD backlight drive circuit. The working voltage of MP1541DJ chip is $\mathrm{VDD}=5 \mathrm{~V}$, and the conversion frequency is $1.3 \mathrm{MHz}$.
The chip can output up to $12 \mathrm{~V}, 200 \mathrm{~mA}$ under normal working conditions. The chip has low-voltage self-locking function, output current-limiting protection, and overheating protection. It only needs a few peripheral devices to work normally. Based on the MP1541DJ LCD backlight drive circuit design, the output current of the VLED pin is adjusted by adjusting the resistance of R37, so as to adjust the brightness of the LCD.

DSP module controls the data acquisition and processing of various sensors, and sends the collected data to the ARM module through the serial port. Then, it is sent to the background WEB monitoring server through GPRS, and the data is stored, displayed, and analysed locally and remotely. In addition, DSP module receives commands from the ARM module and the WEB server, and sets and modifies the data acquisition parameters accordingly. Therefore, DSP terminal program contains vibration signal acquisition and processing program, serial communication program, and GPRS remote communication program. The overall program flow chart of DSP data acquisition and processing program is shown in Figure 4.

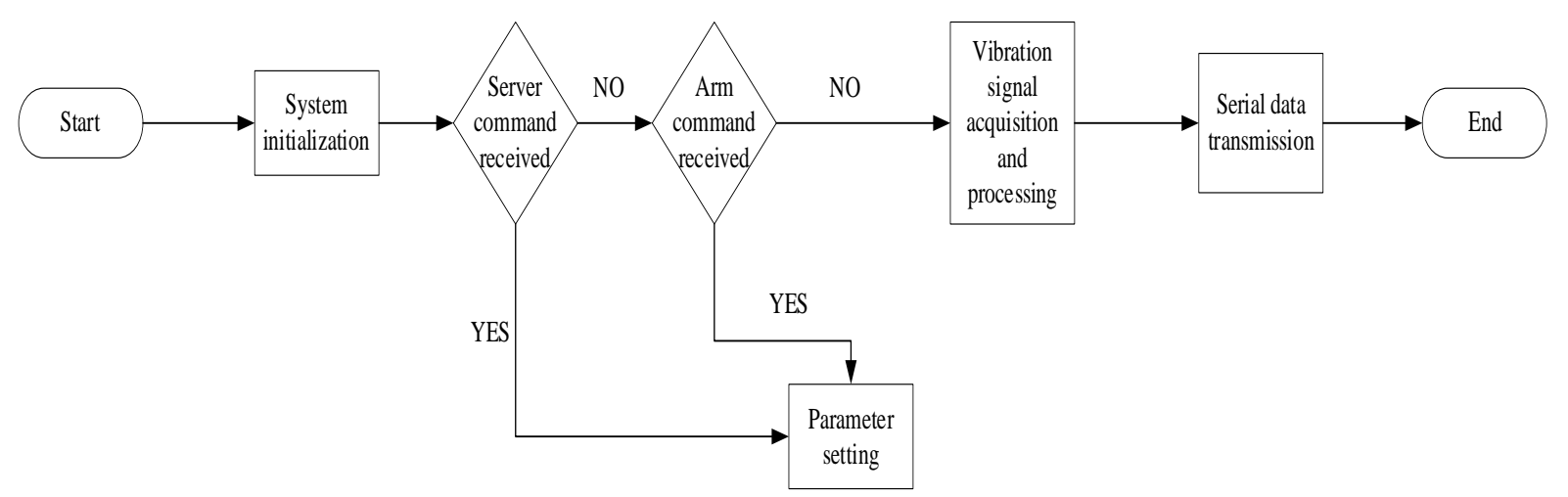

Figure 4: Flow charts of the overall program of DSP data acquisition and processing

dsPIC30F6014A has a 12-bit successive approximation A/D converter with a maximum conversion rate of $200 \mathrm{ksps}$ and 16 analogue input channels. The CHOSA $<3: 0>$ bits of the ADCHS register are controlled by software to select different sampling channels. AD sampling and conversion can be triggered by internal software or hardware. It is configured to start sampling and conversion after Timer3 comparison ends, so the timing period of Timer3 is the signal AD sampling period. Since the timer clock $\mathrm{FCY}=7.3728 \mathrm{MHz}$, the period register of Timer3 is calculated for a specific sampling rate $S$, PR3=FCY/S. Since Timer3 is a 16 -bit timer, $0<$ PR3 $<65535$, and it is deduced that the sampling rate $\mathrm{S}>$ $112 \mathrm{~Hz}$. The $\mathrm{ADCS}<5: 0>$ bits in the $\mathrm{AD}$ control register ADCON3 control the selection of the AD conversion clock cycle.

$$
T_{A D}=T_{C Y} * 0.5 *(\mathrm{ADCS}<5: 0>+1)
$$

In equation (3), $T_{C Y}$ is the clock cycle. The clock cycle in this model is $T_{C Y}=1 / 7372800=135 \mathrm{~ns}$. The minimum value of the conversion clock $T_{A D}$ of the A/D converter of the dsPIC30F6014A chip is 334ns, so $A D C S<5: 0>$ must be greater than 4 according to calculation. A complete AD conversion of the A/D converter of the dsPIC30F6014A chip includes sampling time and conversion time, and a total of $\mathrm{TAD}+14 \mathrm{TAD}=15 \mathrm{TAD}$ is required. When $\mathrm{ADCS}<5: 0>$ $=4,15 \mathrm{TAD}=5 \mathrm{us}$, and the maximum sampling rate $\mathrm{S}$ of the A/D converter is $200 \mathrm{KHz}$. Based on the above calculations, $37<\mathrm{PR} 3<65535$ is obtained, that is, the sampling rate range is $112 \mathrm{~Hz}<\mathrm{S}<200 \mathrm{KHz}$.

512-point data sampling is performed through software settings, and then processed by dsPIC30F6014A, that is, fast Fourier transform is performed on the time-domain vibration signal. Data processing and analysis are easily realized via the digital signal processing function library provided by the dsPIC30F6014A microprocessor. The adopted 
functions are fast Fourier transform function FFTComplexIP0 and code position inversion function BitReverseComplex in the function library provided by dsPIC30F6014A. The specific procedure is as follows.

1. Transform the original data to satisfy the requirements of the FFTComplexIP() function on the input data;

2. Call the FFTComplexIP0 function to perform fast Fourier transform on the transformed timedomain vibration data;

3. Call the BitReverseComplex( function to invert the code position of the output result after the fast Fourier transform to obtain the result of the natural order, for the order of the results obtained by the FFTComplexIP() function is inverted;
4. Local data storage and display, that is, call the serial port program to send the data to the ARM module for storage, and display the waveform through the LCD screen;

5. Send data remotely, that is, call the remote communication module SIM900A to send the original vibration sampling data and the data after the fast Fourier transform to the background WEB server.

$\mathrm{V}$. The structure of the wind turbine generator gearbox.

Figure 5 is a simplified schematic diagram of the internal structure of the gearbox utilized in the experiment, which uses I, II, and III three-stage gear transmission.

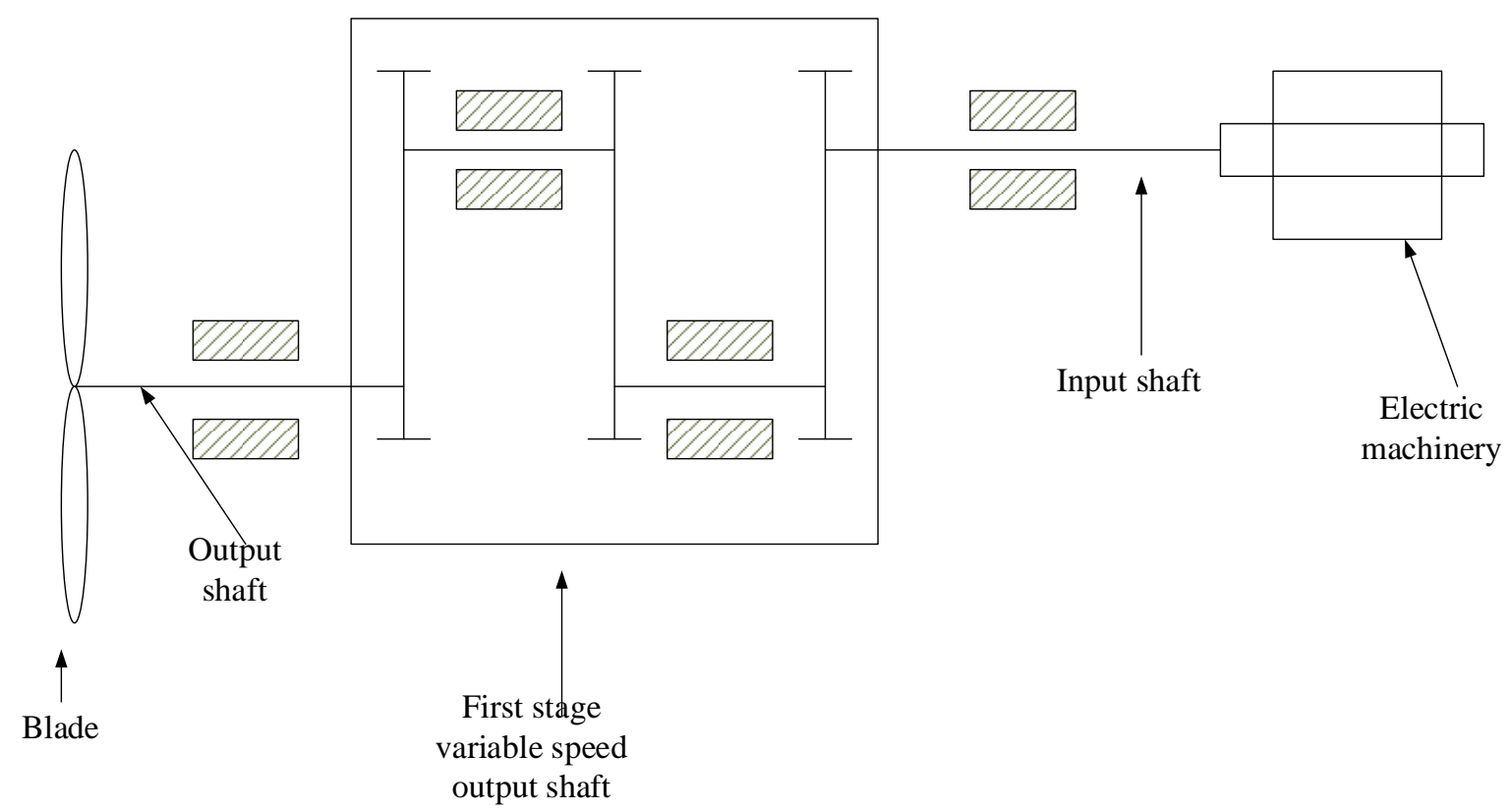

Figure 5: Schematic diagrams of the internal structure of the gearbox

\section{Analysis of Experimental Results 3.1 Simulation Results of Wind Turbine Generator Gearbox}

The speed of the input shaft of the gearbox (wind wheel main shaft) is $20 \mathrm{r} / \mathrm{min}$, and the speed of the output shaft, which is the input shaft of the generator, is $1800 \mathrm{r} / \mathrm{min}$. The detailed transmission parameters of each level of the gearbox are shown in Table 1 (A, B, and C represent the first, second, and third transmission process, respectively).

Table 1 Transmission parameters of all levels of gears in the gearbox

\begin{tabular}{cccccccc}
\hline & ISS (r/min) & OSS (r/min) & AWF (Hz) & FCOD (Hz) & $\mathrm{Z}_{1}$ & $\mathrm{Z}_{2}$ & GMF (Hz) \\
\hline $\mathrm{A}$ & 30 & 200 & 0.33 & 1.67 & - & - & 65 \\
$\mathrm{~B}$ & 200 & 700 & 1.77 & 12 & 84 & 12 & 140 \\
$\mathrm{C}$ & 800 & 1700 & 15 & 36 & 65 & 20 & 700 \\
\hline
\end{tabular}

Note: (ISS: input shaft speed; OSS: output shaft speed; AWF: active rotation frequency; FCOD: driven rotation frequency; $Z_{1}$ : number of driving gear teeth; $Z_{2}$ : number of driven gear teeth; GMF: meshing frequency.)

I. Gear wear change graph.

Figure 6 is the time and frequency change curve of wind turbine generator $\mathrm{A}$ under normal conditions.
Figure 7 is the time and frequency change curve of wind turbine generator $\mathrm{B}$ under worn gear. 


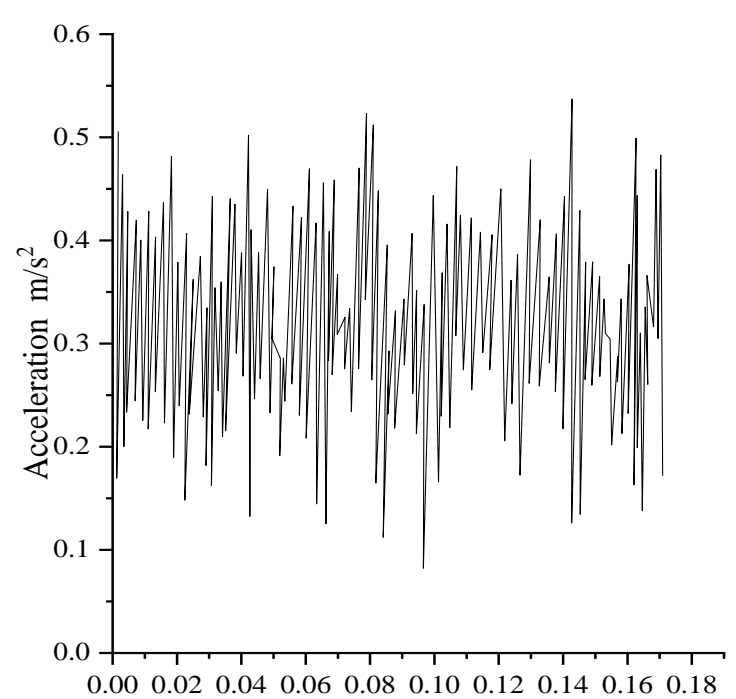

(a) Time $/ \mathrm{s}$

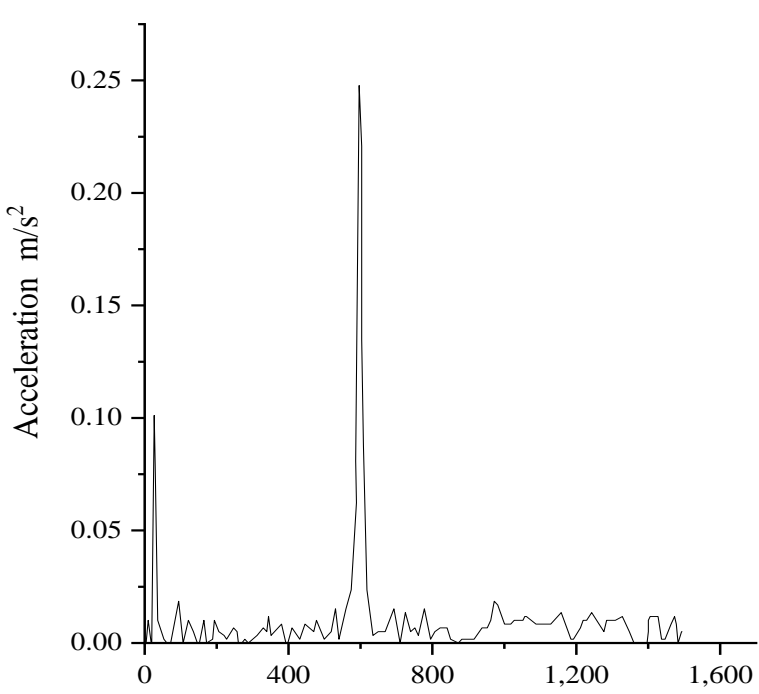

(b)Frequentcy $/ \mathrm{Hz}$

Figure 6: Vibration data curve of measuring point M6 of wind turbine generator A under normal operation. (a): time change; (b): frequency change.

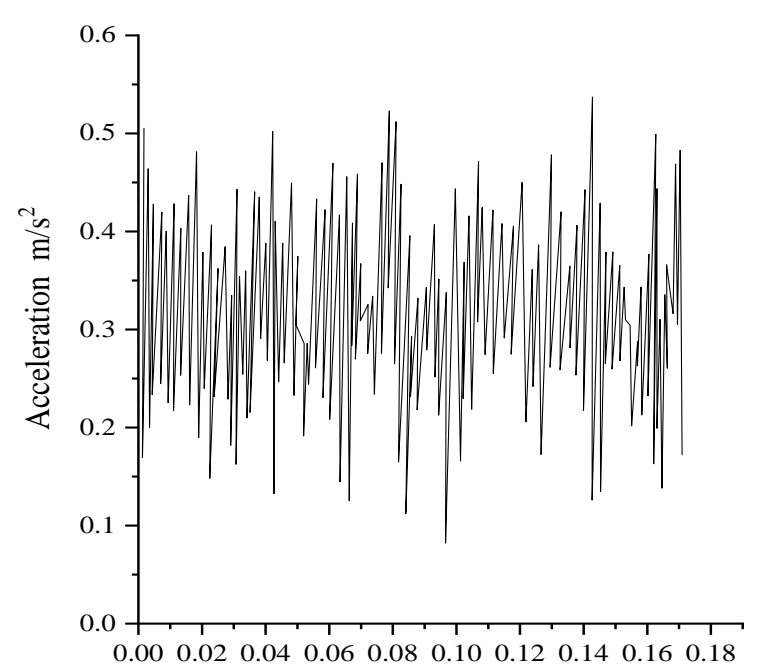

(a) Time $/ \mathrm{s}$

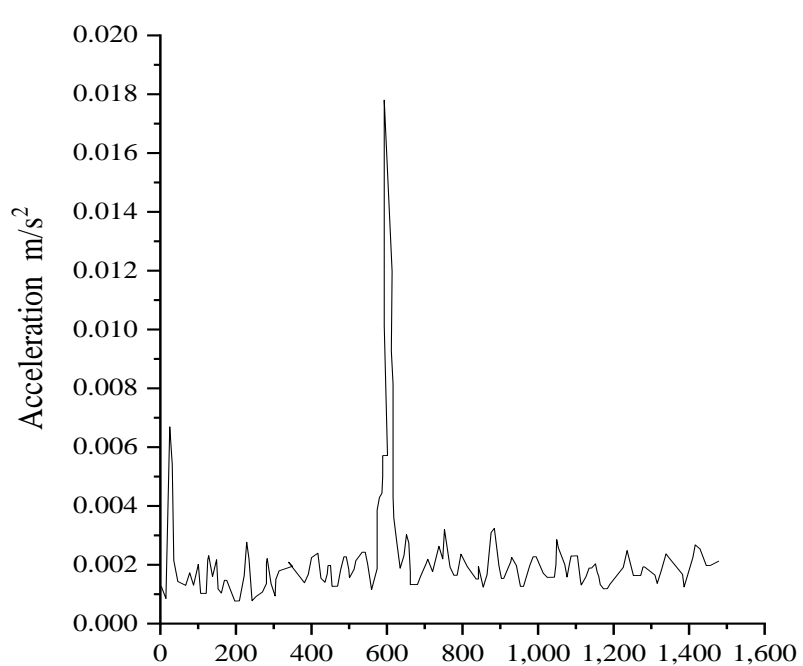

(b) Frequency $/ \mathrm{Hz}$

Figure 7: Vibration data curve of measuring point M5 of wind turbine generator B under worn gear.

(a): time change; (b): frequency change.

In this experiment, two wind turbine generators are selected. Figure 6 is a graph of the time and frequency changes of wind turbine generator A under normal conditions. Figure 7 is the time and frequency change curve diagram of wind turbine generator B under worn gear. The amplitude of the time-domain vibration signal at the M6 measuring point of generator B is obviously greater than the vibration amplitude of the M6 measuring point of generator $\mathrm{A}$, suggesting that the gear at measuring point M6 of generator B is worn out, which leads to increased vibration energy.
However, there are no other obvious frequency modulation components on the spectrogram, indicating that there is no single gear failure at the measurement point $\mathrm{M} 6$ of generator $\mathrm{B}$.

\subsection{Gear break failure}

Figure 8 shows the time change and frequency change in the case of tooth broken in wind turbine generator $\mathrm{C}$. 


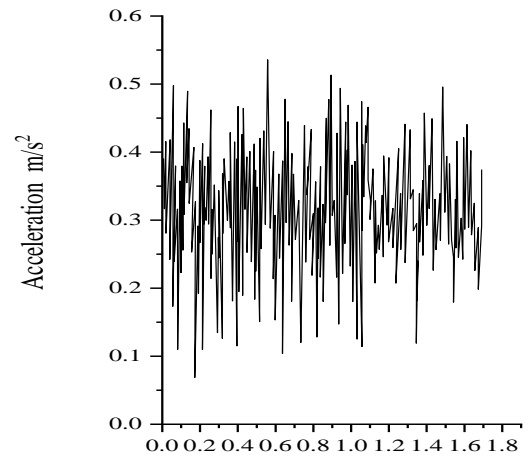

(a)Time $/ \mathrm{s}$

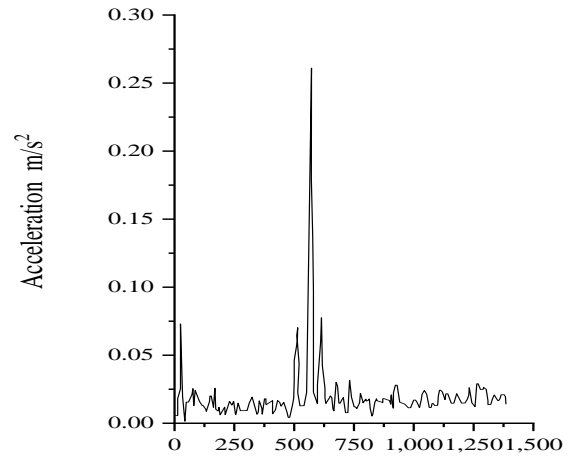

(b)Frequency /Hz

Figure 8: Vibration data curve of measuring point M6 of wind turbine generator $C$ under broken gear. (a): time change; (b): frequency change.

Figure $8(\mathrm{a})$ is the vibration data curve of measuring point $\mathrm{M} 6$ of wind turbine generator $\mathrm{C}$. Figure $8(\mathrm{~B})$ is the gear meshing frequency modulated by two times the rotation frequency of the shaft where the gear is located. The gear failure at measuring point M6 can be predicted. After actual inspection, it is found that one of the gears of the gearbox of this generator is broken.

\subsection{Bearing Pitting Failure}

Figure 9(a) and Figure 9 (b) are the vibration data changes of measuring point M4 under normal conditions, Figure 9(c) and Figure 9(d) are the vibration data changes of measuring point M4 under fault conditions.

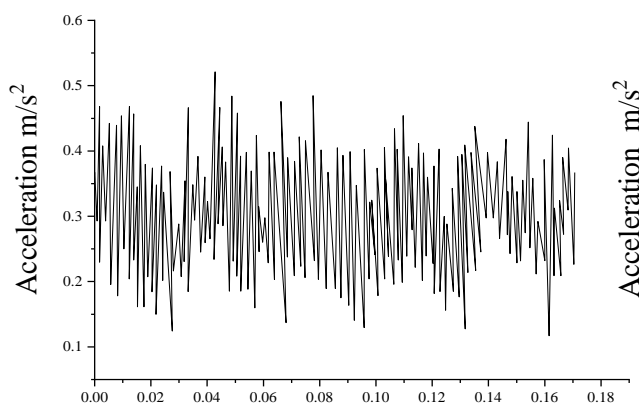

(a) Time $/ \mathrm{s}$

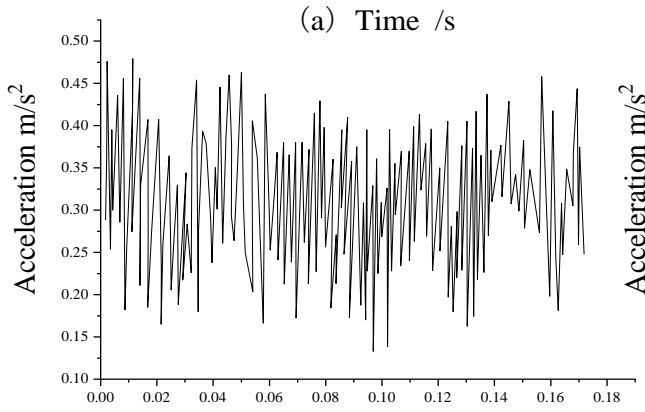

(c) Time $/ \mathrm{s}$

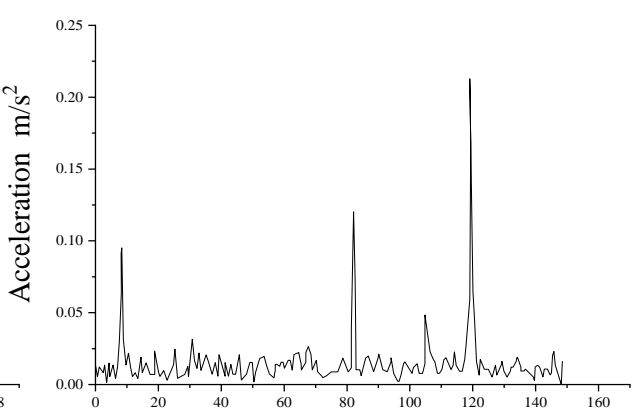

(b) Frequency $/ \mathrm{Hz}$

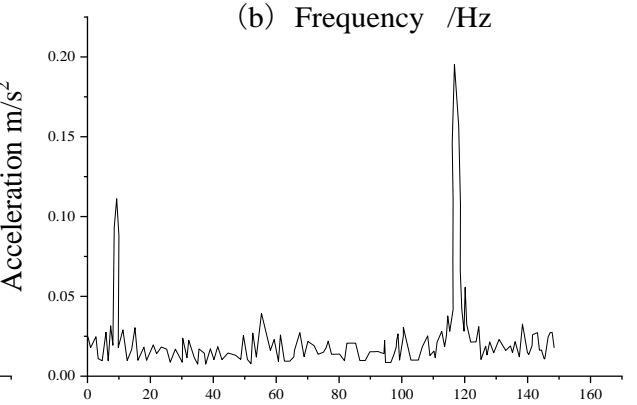

(d) Frequency $/ \mathrm{Hz}$

Figure 9: Acceleration vibration data curves at M4 measuring point when the fan is running normally. (a) and (c) are time changes; (b) and (d) are frequency changes

Figure $9(\mathrm{c})$ and $9(\mathrm{~d})$ are the front bearing of the II-level variable speed output shaft at measuring point M4. Combined with its time domain diagram and frequency domain diagram, the rotating frequency of the shaft is about $10 \mathrm{~Hz}$, and the gear meshing frequency is about $118 \mathrm{~Hz}$, compared with the data of measuring point M4 under normal operating conditions of the unit in Figure 9(a) and 9(b).

\section{Conclusion}

The design and debugging of each sensor data acquisition circuit in the hardware part includes DSP hardware interface circuit design, SIM900A wireless communication module circuit design, and ARM human-computer interaction main control board circuit design. Wind turbine generator gearbox inspection software mainly includes three parts, 
namely DSP end data acquisition and processing program, ARM end human-computer interaction and video processing program, and background WEB server program. DSP terminal program is responsible for the collection and processing of various sensor data, and controls the GPRS remote communication module for data communication. ARM program is responsible for storing the data sent from the DSP, performing data display and user parameter setting, and controlling the USB camera for video processing. The background WEB server program facilitates the wind farm turbine operation and maintenance personnel to browse and monitor the operation status of the gearbox in real time.

Through the actual engineering experiment and a long time of continuous operation, it is proved that this model can stably finish the collection, uploading, and analysis of various data, with real-time monitoring, real-time analysis, and real-time alarm features. It can accurately and timely detect and locate the fault situation of the gearbox, so as to ensure the intelligent analysis of wind turbine generator through big data. Therefore, the safe operation of the gearbox is ensured. The healthy progression of the wind power industry has reference significance.

\section{References}

[1]Feby A. P., Hajime M. (2018) Maximum Power Point Tracking of Multi-Input Inverter for Connected Hybrid PV/Wind Power System Considering Voltage Limitation in Grid International Review on Modelling and Simulations (IREMOS), 11(3), 143-150.

[2]Yang H.N. (2020) The Role of Mathematical Model of Energy Storage by Power Systems Computer Aided Design / Electromagnetic Transients including DC in Power Energy Security Control. IOP Conference Series: Earth and Environmental Science, 558(5), 052038.

[3]Morató A., Sriramula S. (2021) Calibration of safety factors for offshore wind turbine support structures using fully coupled simulations. Marine Structures, 75, 102880.

[4]Lakshmanan S., Prakash M. (2020) Stabilisation of event-triggered-based neural network control system and its application to wind power generation systems. IET Control Theory \& Applications ,14(10), 1321-1333

[5]Wang B. K., Sun W. L., Wang H. W., et al. (2021) Location Determination of Impact on the Wind Turbine Blade Surface Based on the FBG and the Time Difference [J]. Sensors,21(1), 232-232.

[6]Sitharthan R., Sundarabalan C. K., Devabalaji K. R. (2018) Improved fault ride through capability of DFIG-wind turbines using customized dynamic voltage restorer. Sustainable Cities and Society, 39, 114-125.

[7]Anais J., Ali M. (2021) Crack growth direction effects on corrosion-fatigue behaviour of offshore wind turbine steel weldments. Marine Structures,75, 102881
[8]Li Z. Y., Liu C. X. (2021) Research on calculation of spinning reserve capacity of wind power system considering multiple uncertainties. IOP Conference Series: Earth and Environmental Science, 632(3), 032056.

[9]Wang C., Zhang Z., Oveis A., et al. (2021) Modelling and analysis of a microgrid considering the uncertainty in renewable energy resources, energy storage systems and demand management in electrical retail market. Journal of Energy Storage, 33, 102111.

[10]Wang C., Zhang H. L., Fan W. H, et al. (2018) Chaos (Woodbury, N.Y.),28(1), 013-102.

[11]He L. J. (2019) DC Bus Voltage Adaptive Control for DC Microgrid with Wind Power Generator Systems. International Core Journal of Engineering, 5(10), 32.

[12]Brian H., Ger K., Andrew C. (2021) Structural analysis of an offshore vertical axis wind turbine composite blade experiencing an extreme wind load. Marine Structures, 75, 102858.

[13]Tian H., Xu X. F., Lin H. (2019) Simulation study on direct-drive wind power system. The Journal of Engineering, (23), 9183-9189.

[14]Rodrigo S. V., Sirko B., Jörg A, et al. (2020) Determination of the angle of attack on a research wind turbine rotor blade using surface pressure measurements. Wind Energy Science, 5(4), 1771-1792.

[15]Jin S. H. (2019) An Innovative Wind Project on the Development of a 10 MW Class Superconducting Wind Power System Fully Sponsored by KEPCO. Superconductivity and Cryogenics, 21(2), 2-6.

[16] Jan S., Xie X. R., Yan G. G. (2019) Mitigating subsynchronous control interaction in wind power systems: Existing techniques and open challenges. Renewable and Sustainable Energy Reviews, 108, 330-346.

[17]Lotter J.T., Naidoo R., Bansal R.C. (2017) The Effects of Distributed Generation Sources within Commercial Retail Reticulation Networks. Energy Procedia, 142, 1765-1770.

[18]Prodóssimo S. A., Lima A. A., FernandoCosta A L. (2020) Direct method for transient stability assessment of a single wind turbine generator subject to LVRT requirements. IET Generation, Transmission \& Distribution, 14(25), 13-25.

[19]Tong M.H., Zhu W.D., Zhao X., et al. (2020) Free and Forced Vibration Analysis of H-type and Hybrid Vertical-Axis Wind Turbines. Energies,13(24), 6747-6747.

[20]Wang Y., Wu X. H., Li Z. H. (2020) Vector-fittingbased quantitative SSCI analysis for seriescompensated wind power systems. IET Renewable Power Generation, 14(15), 30233034.

[21]Kamran S., Horia H., Curran C. (2020) Experimental and numerical simulation of extreme operational conditions for horizontal axis wind turbines based on the IEC standard. Wind Energy Science, 5(4), 1755-1770. 